\title{
The Value of an HR Professional Group for Organizational Learning
}

\author{
Vivienne Griggs, University of Leeds, UK \\ Jenny Allen, Formerly NHS Digital, UK
}

\begin{abstract}
This paper reports on the value of the HR Professional Group at NHS Digital. A partnership between an academic researcher and an HR practitioner was adopted to bring together organizational knowledge with extant research. The study examined the lived experiences of members of the HR Professional Group in relation to social learning activities. Thirteen interviews were conducted with members of the HR Professional Group. A thematic analysis was undertaken on the resultant narratives. Three key themes emerged from the analysis. These were: strategic direction and ownership; professional identity and knowledge sharing; reflection and transfer of learning. The findings suggest professional groups offer a means of developing an expert learning community through the integration of research, practice, reflection, and knowledge sharing. By offering development beyond current job roles it contributes to talent development within the organization. Drawing on the findings, a model is proposed for professional groups which offers both development for the existing groups at NHS Digital and a template for HRD practitioners wishing to develop professional learning communities in their organizations. The proposed outcomes relate both to action for the organization and a contribution to knowledge in this field.
\end{abstract}

Key words: organizational learning, HR, professional development, identity, community of practice

\section{Introduction}

This article offers a reflection on practice regarding an approach to professional learning at NHS Digital. NHS Digital is an executive, non-departmental public body and is the national (England) provider of information, data and IT systems for patients, service users, clinicians, commissioners, analysts, and researchers across health and social care. The organization's role is to improve health and social care in England by putting technology, data, and information to work. NHS Digital has been positioned at the forefront of the government's national agenda to radically reshape and digitize patient experiences within both the health and care system.

The HR Professional Group is a forum where HR professionals in the organization can collaborate and share knowledge around professional practice. Professional Groups were launched across NHS Digital shortly after the organization's creation in April 2013 with the aim of building and sustaining a professional workforce developing individual capability in support of organizational strategy. As well as aiming to build vibrant professional communities across the organization, to share knowledge and develop standard ways of working, it was also hoped that professional groups would provide a clear view of relevant professional training requirements and support staff in shaping career paths with professional competencies and consistent job descriptions. At that time, these objectives directly supported NHS Digital's strategic workforce ambitions to be more flexible, to develop staff, and to facilitate resourcing and recruitment into the organization. 
It was also felt they would help to respond to feedback from the annual staff survey about professional development and equality of opportunity.

The purpose of the HR Professional Group is to develop members' capabilities; to generate and exchange knowledge. Whilst most definitions of talent development focus on identified groups of workers, the definition by Garavan, Carbery and Rock $(2012$, p. 6) could encompass the more inclusive approach to talent development taken here:

Talent development focuses on the planning, selection and implementation of development strategies for the entire talent pool to ensure that the organization has both the current and future talent supply to meet strategic objectives.

Talent development as a means of building capability and flexibility has much to offer to an organization like NHS Digital which was going through a period of organizational transformation. Investment in talent development practices have been seen to have benefits to the organization broader than the intended learning outcomes, such as attracting talent to the organization (Kucherov \& Zavyalova, 2012); affective commitment (Chami-Malaeb \& Garavan, 2013). However, Human Resource Development literature has focused on identifying talent, talent pools, talent pool strategies (Lewis \& Heckman, 2006) seeing talent development as an activity targeted at selected individuals rather than a strategy for a more collective form of organizational development. Garavan et al. suggest "talent development is a significantly under-developed and under-researched concept" (2012, p.14), with evidence suggesting organizations are designing customized talent development for their organization but often focused on leadership rather than broader workforce development. This study of the professional group approach at NHS Digital, therefore, offers a rare insight into the approach adopted by one organization to take an inclusive, group approach to talent development.

As a particular learning initiative, the Professional Group is less easy to categorize. Although the group fits within the broader concept of talent development it does not easily match the list of interventions cited in the literature. Whilst team learning has begun to attract more attention, the distinction between a team with interdependence and a group of this size with more diverse roles and a lack of interdependency is more elusive in the literature. Where large group interventions are explored, for example, appreciative enquiry (Cooperrider \& Whitney, 2001) or open space technology (Owen, 1997), they are often seen as a more innovative approach rather than a more traditional form of workplace learning. The approach to professional groups seems more aligned to networks often developed in organizations to support the learning of particular groups e.g. female managers, BME groups, graduates etc. (see for example: Bierema, 2005; Friedman \& Holtom, 2002; Cromwell \& Kolb, 2004).

Beyond the research around specific groups of workers the closest alignment to extant research for this more inclusive approach to development appears to be in the sphere of Communities of Practice (Lave \& Wenger, 1991). The stated aim of the group aligns to some extent with notions of Communities of Practice and Wenger's definition:

Communities of practice are groups of people who share a concern or a passion for something they do and learn how to do it better as they interact regularly $(2011$, p. 1$)$.

Other research on developing professional learning communities has been done in education and healthcare settings. Following a review of the literature in schools, Stoll et al. (2006) concluded that developing such communities had potential for building capacity and sustaining 
improvements. De Groot et al. (2014) discuss how learning communities can support continuous development for autonomous healthcare professionals.

As such this examination of an inclusive approach to talent development makes an important contribution to the literature.

\section{Context of the Research}

\section{Background to the NHS Digital HR Professional Group}

The NHS Digital's initial initiative in respect of an HR Professional Group was originally led by the Head of HR within the organization, a senior member of the HR department leading $30 \mathrm{HR}$ staff and responsible for the provision of HR services to the organization.

At the time of the study, the HR Professional Group had 48 members with 25 employed in the organization's HR department and the remaining contingent largely operating as trainers and in training quality assurance roles across the organization. Shortly after the primary research associated with this study took place, the organization implemented a new operating model on 1 April 2016 placing professional groups at the heart of the organization's design and structure. With this most recent organizational transformation, selection into the relevant professional group is now mandatory i.e. if someone is employed within the organization as an HR professional as articulated in the definition above, they are now automatically assigned to this professional group.

Prior to 1 April 2016, the group had focused efforts in a number of areas including the development of standard job descriptions, agreement to utilize the CIPD professional competency framework and the development of a training and qualifications framework. Considerable effort had also been afforded to the establishment and running of a schedule of professional development activities and events which have included the introduction of external speakers to the group on a variety of HR and people related topics as well as the undertaking of self-assessment activities and analysis of those.

\section{Study collaboration}

The original Head of the HR profession is the co-author of this study and was the HR professional lead at the time the research was carried out. Subsequent to the study but not as a result of it, the leadership of the HR profession changed as the previous Head of HR secured a new position within the new organizational structure. It should also be noted that the Head of HR who collaborated on the research has now in fact left NHS Digital altogether.

\section{Methodology}

The aim of this study was to investigate the value of the HR Professional Group at NHS Digital, formerly UK Health and Social Care Information Centre (HSCIC) in "a spirit of collaboration and co-inquiry" (Shani \& Pasmore, 1985, p. 439). An inductive philosophy underpinned the research. The intention was to gain an understanding of the ways people explain and make sense of their experiences at work so a qualitative research design was considered appropriate. One 
to one interviews were chosen as a way of exploring the individual perceptions of members of the group. In line with the inductive approach, the discussions were very open, flowing from the participants' comments rather than a set list of questions. The focus therefore was a discussion allowing the participant to freely express themselves rather than a formal interview structure.

Inductive analysis means that the patterns, themes, and categories of analysis come from the data; they emerge out of the data rather than being imposed on them prior to data collection and analysis (Patton, 1980, p. 306).

Thus with the adoption of a qualitative research design, members of the group were invited to an interview to reflect on their engagement with the HR Professional Group. Participation was voluntary and conduct of the interview complied with research ethics guidance. A participant information sheet and consent form were presented at the outset of the interview.

Exploratory interviews were conducted with thirteen members of the HR Professional Group at NHS Digital. These included staff at different levels of seniority and crossing both HR and OD responsibilities.

A thematic analysis was undertaken to identify themes emerging from the individual narratives. "Thematic analysis is a method for identifying, analysing, and reporting patterns (themes) within data" (Braun \& Clarke, 2006 p. 6). The inductive codes were derived bottom-up from the researcher's reading of the data; this data driven approach was appropriate for this study without trying to fit information into a pre-existing theoretical coding frame. The analysis thus sought to identify important patterns in the participants' views and experiences. This was done by constructing mind maps for each individual interview highlighting the key topics and connections between different areas of the discussion. Through consideration of a number of individual mind maps repeated issues began to emerge and a concept map was developed. This enabled further analysis to be guided by the concept map to identify relevant data in relation to the identified themes. Themes were refined, additional themes or unique ideas were also recorded.

\section{Limitations}

The interviews were conducted with volunteers who agreed to take part. This may not be representative of the full HR Professional Group and indeed may exclude some of the more adverse viewpoints. Further, although the interviewer was not a member of NHS Digital, the participants knew that the research was conducted in partnership with Head of the HR professional at the time and although anonymity was assured this may have influenced some responses.

The researcher approached the analysis with some pre-existing knowledge and therefore as noted by Braun and Clarke (2006, p. 6) "data are not coded in an epistemological vacuum". Interpretive analysis is subjective and open to bias and a different researcher may have classified the themes in a different way.

We were also reliant on data from a single interview with each participant; a longitudinal study collecting views following several HR Professional Group meetings might provide a richer account than a general overview of experiences. 


\section{Findings}

Six themes initially emerged from the interviews with the members of the group; these were: professional identity, teamwork, personal development, the nature of learning, leadership, and learning transfer. These were later refined to three key themes: professional identity and knowledge sharing (which included teamwork); space for reflection and development (which included personal development, the nature of learning and transfer), strategic direction and ownership (this incorporated leadership). The three resulting themes are closely integrated and whilst there are areas of overlap they provide three significant components of the professional group. The findings below set out these key themes.

\section{Strategic direction and ownership}

The group was perceived to have strong leadership with a clear vision and setting of direction from the HR professional lead. Members talked about it being "set up in line with organizational objectives", and there were references to the HR professional lead setting the vision and driving the group. Some members referenced other professional groups in the organization where the leadership had not been as strong and where as a consequence the group was far more immature. The leadership extended to determining what would be appropriate topics and setting the agenda. The evident commitment and importance placed on the group meetings resulted in members seeing it as high priority and feeling there was an expectation they should attend. Some members spoke about involvement in setting the direction with one interviewee suggesting it was an opportunity to discuss what the service should look like going forward, another spoke about how the group had evolved and "I've had a part to play in that", and another spoke about "an ideas committee" talking about what might be of interest to the group. However, although most felt they could contribute to the content and schedule of events the majority appeared to be passive in this regard. Certainly some felt they had collective responsibility to develop the profession and contribute their expertise but in reality the content was determined by a small number and the encouragement to contribute was not enacted. Some members felt this was something that needed to change going forward; suggesting more people needed to feed into setting the agenda, that is needs more collective responsibility and engagement, and that everyone should have responsibility to contribute if they want to be involved. One commented it "should be embedded not her group" and another "too much push rather than pulling".

An aspect of the strategic direction of the group which was more contentious was the membership of the group. This related to two particular groups of people: the trainers and the HR administrators. At the outset the group members self-selected but as things have developed in the organization there have been clearer guidelines on membership and everyone is expected to align to a professional group. The HR Professional Group has wider membership than the HR team and this was valued by many of the participants. The group nominally has two strands: HR and Organizational Development and Learning. The latter strand incorporates a number of trainers working outside of the HR team in the organization. Although no trainers took part in the interviews, some of the other participants raised concerns about whether the content was as relevant for them. There were some examples of how building relationships in the group had led to working together on projects and the trainers were viewed to have a shared skill set and shared interests with other members of the group. It was suggested, however, that their attendance was less frequent. This may be due to location and the nature of their roles but raises an interesting 
question about the link between attendance/engagement and the individual's personal alignment with the group.

Whilst inclusion of the trainers was commented upon, exclusion of the HR administrators was also remarked on by a number of participants. As groups were determined on professions rather than departments, the HR administrators were aligned to the Business Administration Professional Group. There was a difference of opinion about whether the administrators were welcome to attend the HR Professional Group meetings but it was clear that they were not viewed as official members of the group. Some felt this did not reflect the administrators' aspirations to pursue a career in HR and by excluding them from the group when they were part of the HR team could lead to them to feeling they weren't valued.

The distinction made by some members between a Community of Practice and a Community of Interest also addressed the issue of membership, with the core group having the potential to evolve into a Community of Practice, and the wider group representing anyone with an interest in the profession.

\section{Professional identity and knowledge sharing}

There was a strong focus on the group creating professional identity for the HR professionals. One member described this as "sharing good practice to develop you as a professional". It was seen as a "community and we look at best practice", and a way to "represent myself within the profession". This linked to consistency, clear expectations and raising standards through coming together as part of a professional group. For example "to raise standards and ensure consistency across the profession and making sure that we are all up to date with our professional knowledge" and "it's about bettering our performance as a team". This was a common response, as one member put it "a group of like-minded professionals coming together to discuss pertinent issues". but with a strong focus on learning and development: "part of my cpd" "forum for people to come along and learn". The external focus of some of the meetings was seen as an important contributor to this by offering different perspectives, challenging the current ways of working and demonstrating best practice as demonstrated in the following comments: "helpful to know what's going on outside"; "understanding the bigger picture and trying to put into context what it is we do as a profession"; "opportunity to underpin our operational practice with some of the theory that's important". Some participants referred to the group as a Community of Practice or a Community of Interest, suggesting the professional group more closely aligns with the latter concept and other work groups, such as case conference meetings and which offer more a practice orientation, noting a "distinction between the department and the profession". There was recognition of professional standards through alignment with the Profession Map from the Chartered Institute of Personnel and Development (CIPD); one member even referring to the group as being like a "sub CIPD".

Building appropriate networks both internally and externally was seen as a valuable part of the group. This also linked to developing and harnessing expertise. The group was seen as an important aspect of teamwork within the profession. Building relationships, networking at different levels and across work teams, getting to know people, bonding time, an opportunity to challenge each other, open debate, understanding people's roles, collective development, and collaboration were all referred to as positive aspects of the group. One member described it as a 
routine, regular opportunity to learn from each other, and others discussed the value of "getting to know colleagues better - know who to speak to about issues".

The nature of learning taking place at the HR Professional Group meetings emerged as a distinguishing feature of the group. The external speakers introduced a theoretical underpinning and an expert view of subjects which encouraged colleagues to adopt an evidence-based approach to their practice. This was seen as important for "opening our eyes to what's going on out there" and "getting a broader perspective". Most members felt the group addressed relevant and contemporary issues and through a variety of formats which would appeal to different learning styles. The value of informal and emergent learning was acknowledged, for example: "challenging each other from a peer to peer perspective", "we have some healthy debates", and "made me think about ways of approaching things we've done".

Knowledge sharing was a prominent theme in the dialogues although at times the meetings were viewed as more of a presentation rather than a forum for sharing experience. The active engagement of participants is perhaps an area for consideration going forward. This was acknowledged by some participants, for example: "could have done a bit more of sharing our own expertise" and a feeling that some "sit back or feel quite reticent to share themselves".

\section{Reflection and transfer of learning}

The time and space for development afforded by the group was clearly valued by participants. It was seen as an opportunity away from the day job, where they were given time to think and reflect. One member described it as "headspace" and another commented on the chance for "challenging our own expectation". Despite similar membership to other HR meetings the HR Professional Group was viewed as having a different emphasis with a distinct focus on personal and career development rather than work performance. Although not always seen as directly related to work it was viewed as improving performance in a broader sense so there was talk of learning new things, helping people think more broadly, and developing greater personal insights.

One interviewee commented that engagement with professional body (CIPD) meetings often requires a commitment out of working hours which can be difficult with childcare commitments so the option to access development during the working day raises an interesting matter about equality of access. The positioning of the HR Professional Group meetings affords everyone the opportunity to attend and demonstrates that the organization places importance on the development of their staff.

The examples of where people had applied knowledge from the meetings to their work related to specific business areas such as talent management or employment law. Often in relation to transfer participants spoke about developing a wider perspective rather than specific transfer of knowledge. It can be difficult to demonstrate direct transfer in relation to broader development opportunities. Indeed some of the comments implied this was inappropriate, referencing no specific transfer but rather the development of a wider perspective, or reflection on how systems change, and often linking transfer to better networks and understanding what each other does. However for others there appeared to be some missed opportunities in this area. Some participants commented that reflection on learning, and as one person put it "closing the loop", was not apparent. Although one member referred to discussing the meeting with her manager afterwards questioning "is there anything we can do differently as a result of it ... we do think 
about how we can apply it"; for others they "don't take time as a group to reflect before moving onto the next topic" and there is no consideration of whether the learning is embedded. The HR Professional Group was portrayed as a series of presentations/meetings and there was minimal testimony of feedback, reflection or further discussion beyond the actual meetings themselves. Some interviewees stated that they would prefer a stronger link to current work issues (although this perhaps contradicts some of the stated value of the broader professional development focus) but for others it is more about the consolidation of learning rather than moving from one topic to another, "allowing more time for reflection".

\section{Discussion}

We commence this discussion with a detailed practice reflection from the original lead of the HR professional group. This is followed by a set of scholar-practice considerations through which we seek to position and advance our understanding of this particular type of HRD practice as evident within NHS Digital and as a basis for conclusions and implications for HRD practice more generally.

\section{Reflections on findings from a practice perspective: comments from the NHS Digital former lead of HR professional group}

I really welcomed the opportunity to work on this research project investigating the value of the HR professional group at the NHS Digital. This work was undertaken at a particularly timely moment as the organization was transforming to a new Operating Model which placed professions at the centre of the organizational design and business. Prior to the research, the group met on a monthly basis for two hours and there were some members of the group additionally involved and engaged in other professional group activities in and around this session. Given the time, resource and effort which had gone into establishing and maintaining the business of the group, it was really important to understand the value of the group to individual members for whom in effect the group operated prior to the new Operating Model introduction. Additionally as we have now organizationally moved into an arena where professions are much more important in NHS Digital business, there is some invaluable learning for not just the HR profession but other professions across the organization.

My personal reflections centre mainly on the feedback regarding the effectiveness and leadership of the group. I completely recognize that you don't always gain the level of honestly set out in the report of findings if you as a leader ask the question individually of staff or members of any group. The HR professional group was acknowledged as having strong leadership and I appreciate and welcome this feedback. Equally I welcome the feedback that effectively some members of the group felt more engaged and able to influence the direction of the group than others. Engaging with individuals and groups of staff to work towards a common and shared goal is something I am passionate about and do try to engender, however, there are some subtleties around this in terms of continuing to check in during the lifecycle of the work on how people are feeling and bringing out the contributions of those who are less vocal. This is a really important and timely reminder for me.

Professionally, I think it is very encouraging that there is a shared recognition revealed in this research that the HR professional group is an established forum and part of the fabric of the organization. Additionally, I welcome that the HR professional group members recognize that a professional identity for HR has been established in the organization and embedded in the consciousness of HR professionals in the NHS Digital. The acknowledgement of the CIPD profession map is also very positive as the recognized set of standards for HR professionals in the organization. 
The research has also helpfully confirmed that individual members of the group welcome the focus of the profession on personal and career development and that the topics covered in the monthly development sessions were relevant to their working lives and there was significant learning from these. Some of the group members acknowledged the theoretical underpinning of these sessions aligned to particular topics - this was the very intention of many of the sessions. The development of any professional expertise and eventually then practice within it needs to have an awareness of key theory and underpinning best practice. This was a deliberate move on my part to ensure that some of that theory and best practice was integrated into professional group sessions to ensure that breadth of thinking amongst HR professionals within the organization.

Whilst all of these observations are excellent foundations for the HR professional group as we are in the early months of the new Operating Model, it is also clear that there is some amendment and adjustment needed to the focus of the group as we move forward. Some of this is necessitated by the objectives of professions established by the organization in our new model but equally it is important not to lose the learning into practice from this research. Specifically, the discussion and findings relating to transfer of learning are key - in some respects is it arguable that there is no learning if this does not happen and some feedback from the research undertaken indicates that there is not always the application in practice following on from the HR professional group session or closing of that loop.

Finally, there is a specific and outstanding question to be addressed regarding membership of the group. It is clear and widely understood that Learning and Development professionals from across the business and not just from within the HR department should form part of the HR professional group. However, I and members of the profession have observed some apparent tensions within this including in terms of content of sessions, and relevance of the sessions to some learning and development professionals' working practice. The question of whether or not the HR Administrators should be formally part of the HR profession remains open or at least is still perceived to be open following on from the research and it is acknowledged that potential further discussion and engagement with those staff impacted on the rationale is required going forward.

\section{Scholar-practice considerations}

The Professional Group at NHS Digital offers a development opportunity for all members of the HR team. This aligns with the concept of generic talent as the potential of all employees (Nilsson \& Ellström, 2012) and fits Wenger's definition of "social communities and constructing identities in relation to these" (1998, p. 4). As an approach it has the potential to be adaptable, collaborative, and responsive to the work context. Some of the interviewees referred to the group as a Community of Practice $(\mathrm{CoP})$. Others made a distinction between a $\mathrm{CoP}$ and a Community of Interest (CoI). It is acknowledged that the use of terms in organizations does not always match the theoretical definitions offered in the HRD literature (the myriad approaches to coaching and mentoring are perhaps one of the most obvious examples). However, from a conceptual viewpoint the professional group does possess some features of a CoP. Wenger (2011) identifies three characteristics crucial to a CoP. Firstly the domain, which in this case is the HR profession; secondly the community, coming together for joint activities, to help each other, share information, interact, and learn together and which closely aligns with the members' descriptions of the professional group and finally the practice. This is perhaps the area at most divergence with the professional group where practice was seen to take place in smaller work teams. However, in a recent series of interviews Wenger-Trayner clarifies that the notion of CoP refers to a social process rather than a group per se and talks about a "learning partnership" so members may engage in the same practice without sharing a common team or task (Farnsworth et al., 2016). In this way the professional group seems to align with this notion. The development 
of competence in a domain over time supports the vision of the professional group; "a mutually negotiated competence" (p. 143) seems particularly relevant.

These three characteristics correspond, to a degree, with the three emerging themes from the interviews. Clearly there is a strong overlap between the themes, but the distinction is made to accentuate the components which are fundamental to the success of the group. The first theme highlighted in the findings is the strategic direction and ownership of the group. This is in part about setting the domain and raised some issues about membership. This was determined in line with the strategic identification of professions within the organization but raised some concerns about the exclusion of administrative staff who were aligned to a different professional group and inclusion of the trainers who felt tangential to the HR group. Whilst self-selection was initially a feature of the professional group, changes to the organization structure have led to directed assignment to the professional groups. The sense that there was a requirement to attend meetings further reinforced this aspect. This is conceivably a strength as the fact that everyone has to take part raises the importance of the group, demonstrates the level of organizational commitment and therefore importance attached to it, and for the emergent and incidental learning to take place people do need to participate. Nevertheless it removes a distinguishing feature of the group which previously set it apart from the department and work structure. So, in this new context, how does the group remain distinctive and offer something of value to the participants beyond their normal working practice? The characteristics of the group emerging from the interviews as valued by the members are essential. The group needs to maintain a focus on personal and career development rather than concentrate on immediate work issues.

Leadership was seen as important in setting the direction and maintaining the momentum of the group. Research in online CoPs has suggested the role of the facilitator is important in maintaining learning over an extended period of time and enhancing the learning aspects (for example, Gray, 2004). This is also indicated in our findings where the leadership had been a driving force in establishing and maintaining the group. Whilst there was recognition by some that shared ownership ought to be a feature of the group it was clear that coordination and support from the manager had maintained the momentum of the group. Although CoPs were initially conceptualized as informal and organic, Wenger and Synder, (2000) develop this to suggest they can be nurtured by organizations by providing an appropriate infrastructure and bringing the right people together. This aligns with the approach at NHS Digital. However, the leadership does present a potential tension. Whilst, it demonstrates commitment from the organization and a vision of learning as important, and similarly supports research on online CoPs about the importance of facilitation to maintain and enhance the group, the counterpart is that it perhaps contributes to a lack of ownership amongst the team, a passive approach to developing the group, where members are happy to take part and enjoy the meetings themselves but are not contributing at a more strategic level. This passivity potentially impacts on the engagement and transfer of learning. Collaboration is also identified as an important characteristic of CoP in organizations, which "enable practitioners to take collective responsibility for managing the knowledge they need, recognizing that, given the proper structure, they are in the best position to do this" (Wenger, 2011, p. 3). So the challenge for NHS Digital is to maintain a senior figurehead and facilitator for the group but develop more collective ownership of the direction and itinerary.

The sense of professional identity was a distinguishing feature and a significant outcome for the group. Wenger-Trayner sees identity as a central concept to CoPs (Farnsworth et al., 2016). Identity construction is fundamental to understanding and explaining key aspects of organizational 
life (see for example, Brown, 2015). A focus on professional identity is perhaps even more important to a profession such as HR which has fought to establish itself as a profession and still undergoes a degree of ambiguity and uncertainty about the domain. Pritchard and Fear (2015, p. 359) describe this as "HR professional insecurity". Developing expertise and identity is therefore essential for professional credibility. Expertise is derived from learning and situated within practice. This professional standing is central to negotiating ethics and accepted codes of conduct for the group and building expert knowledge. The Professional Group in this sense is important for the development of the profession within the organization. As Brown and Duguid (2001, p. 202) state in relation to CoPs:

These groups of interdependent participants provide the work context within which members construct both shared identities and the social context that helps those identities to be shared.

Further, by creating a learning community which brings together external perspectives on theory and best practice with the opportunity to discuss how this applies in the organization the group has the potential to address the fragmentation of knowledge creating systems referred to by Senge and Kim (2013). Certainly their notion of capacity-building by linking research and the learning community were evident in some of the NHS Digital narratives.

However, the situated in practice aspect of the CoP warrants further examination for NHS Digital. At times the meetings were perceived as information giving rather than knowledge sharing. This balance between expert advice and active engagement of participants is something to consider. The nature of learning is interesting as it seems to traverse the formal nature of presentations, expert and theoretical knowledge with emergent and informal learning opportunities. But, there is a sense that the balance isn't quite right yet with some missed opportunities at the informal and knowledge sharing end of the spectrum.

This links to the third theme and creates an opportunity to build on reflection of the formal learning and consider the application in a work context. This would address the perceived lack of transfer to work practice and demonstrate a stronger alignment with work and organizational priorities. Griggs et al. (2016, p. 1) suggest:

A key attribute of reflective practice is its capacity for ongoing purposeful learning in relation to changing and demanding professional work.

and highlight the importance of workplace culture and organizational support to facilitate reflective practice. The meetings offer the HR professional time and space to step back from their normal work and enhancing the reflective elements of the process could generate improved outcomes as:

Reflective practice ... privileges the process of inquiry, leading to an understanding of experiences that may have been overlooked in practice (Raelin, 2002, p. 66).

In the strategies Raelin suggests organizations can adopt to encourage reflective practice, both "building communities" and "learning teams" would fit with the scope of the HR professional group. By engaging in reflection with others there are two simultaneous conversations, one public and one private (Argyris \& Schon, 1974). Although the meetings offered this opportunity which was valued by the members, some noted the missed opportunities here, so the focus was more on the transmission of knowledge and best practice or theoretical perspectives rather than a group reflection. Managers had opportunities to raise issues in other forums but wider sharing might 
support an inclusive talent management approach rather than privilege knowledge for those in management positions. De Groot et al. (2014) suggest that critically reflective behaviour could help communities enhance their learning potential and Raelin (2002) suggests we need managers who can inspire reflection to generate new ways of coping with change. Perhaps this needs to be a more overt role of the group so that increasing the focus on reflection and application of learning from the group could enhance the link to work performance and capacity to respond to organizational change.

On a related note, Wang-Cowham (2011) talks about how creating opportunities for social and collaborative learning can support talent development programmes. This raises a question about how the Professional Group aligns with other development activity in the organization. This may be an opportunity to integrate other development activity with the professional group, to share and consolidate learning and facilitate a more coherent approach to development.

\section{Conclusions and Implications for HRD Practitioners}

Professional groups offer a means of developing an expert learning community through the integration of research, practice, reflection and knowledge sharing. By offering development beyond current job roles it contributes to talent development within the organization, through an attempt to ensure "everyone at all levels works to the top of their potential" (Redford, 2005, p. 20). Drawing on the experience of the HR professional group at NHS Digital and the lessons learnt from the research we propose a model for professional groups in Figure 1 below.

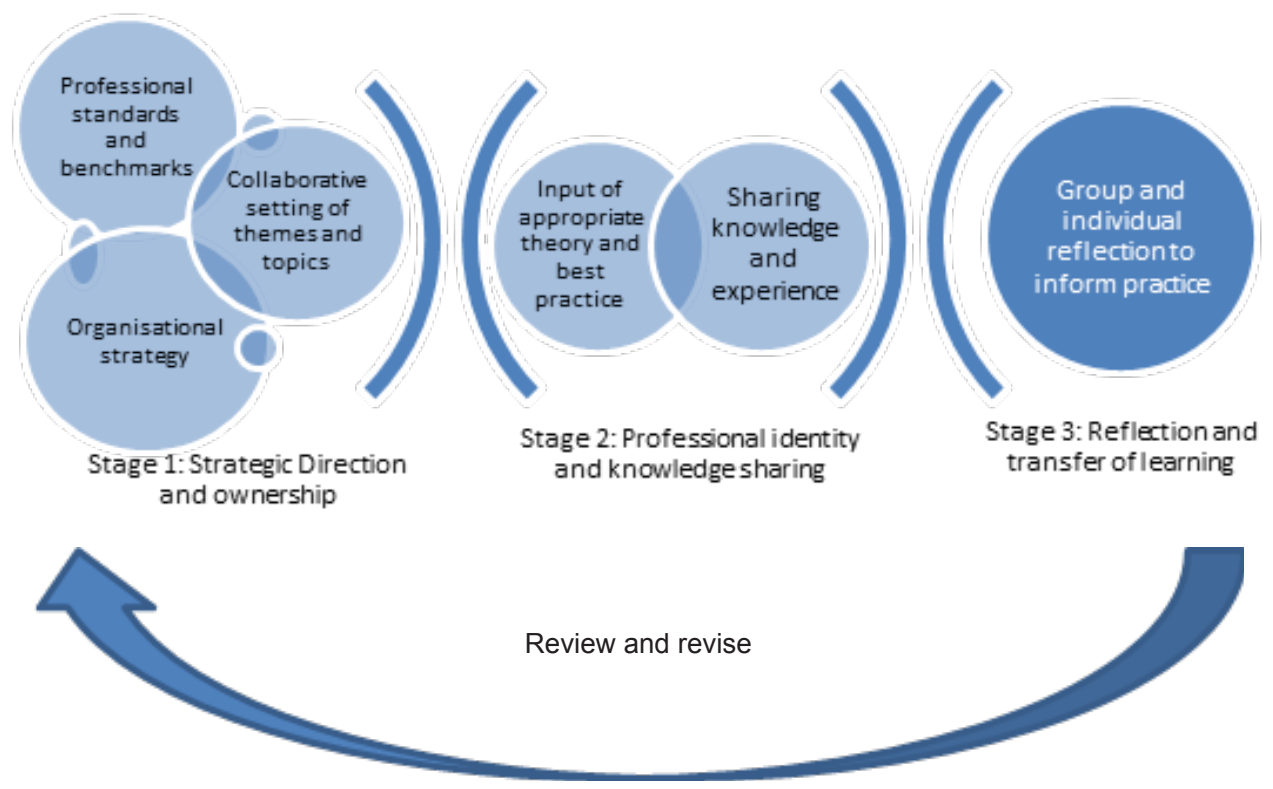

Figure 1: A model for professional groups 


\section{Stage 1 Strategic direction and ownership}

In the set-up of a professional group, the study suggests the senior management support and facilitation was imperative. As the group develops it may be that it could become self-facilitating but until it is established we would see the leadership and facilitation as a pre-requisite. The themes and topics for the group are set collectively by the members but are also aligned with professional standards and the organization's strategy. This ensures the agenda is relevant and future focused. This worked well at NHS Digital and the challenge going forward is to engage members of the team in collective ownership for setting the direction and developing the professional group.

\section{Stage 2 Professional identity and knowledge sharing}

This stage reflects the importance of building professional identity and capability. It focuses on best practice and an external perspective, with value in both formal and emergent learning opportunities. This takes place in the meetings at NHS Digital but could also be done through online communities for other groups.

\section{Stage 3 Reflection and transfer of learning}

This stage is concerned with how the learning from the group is sustained and transferred to professional practice within the organization. For the HR professional group at NHS Digital this is the most immature stage and would warrant further consideration.

Following stage 3 there is a feedback loop so that the process is circular rather than linear, and the group continues to evolve. This offers a way of organizing professional groups or learning communities in the organization that are responsive to organizational and professional requirements and offer both individual and organizational development opportunities.

\section{References}

Argyris, C., \& Schon. D. A. (1974). Theory in Practice: Increasing Professional Effectiveness. San Francisco: Jossey-Bass.

Bierema, L. (2005). Women's Networks: A Career Development Intervention or Impediment? Human Resource Development International, 8(2), 207-224. doi:10.1080/13678860500100517

Braun, V. \& Clarke, V. (2006). Using thematic analysis in psychology. Qualitative Research in Psychology, $3(2), 77-101$.

Brown, A. D. (2015). Identities and identity work in organizations. International Journal of Management Reviews, 17(1), 20-40.

Brown, J. S., \& Duguid, P. (2001). Knowledge and organization: A social-practice perspective. Organization Science, 12(2), 198-213.

Chami-Malaeb, R., \& Garavan, T. (2013). Talent and leadership development practices as drivers of intention to stay in Lebanese organisations: the mediating role of affective commitment. The International Journal of Human Resource Management, 24(21), 4046-4062.

Cooperrider, D. L., \& Whitney, D. (2001). A positive revolution in change: Appreciative inquiry. Public Administration and Public Policy, 87, 611-630.

Cromwell, S. E., \& Kolb, J. A. (2004), An examination of work-environment support factors affecting transfer of supervisory skills training to the workplace. Human Resource Development Quarterly, 15, 449-471. doi: 10.1002/hrdq.1115 
de Groot, E., Endedijk, M. D., Jaarsma, A. D. C., Simons, P. R. J., \& van Beukelen, P. (2014). Critically reflective dialogues in learning communities of professionals. Studies in Continuing Education, 36(1), $15-37$.

Farnsworth, V., Kleanthous, I., \& Wenger-Trayner, E. (2016). Communities of Practice as a Social Theory of Learning: a Conversation with Etienne Wenger. British Journal of Educational Studies. 64(2), 139-160.

Friedman, R. A., \& Holtom, B. (2002). The effects of network groups on minority employee turnover intentions. Human Resource Management, 41, 405-421. doi: 10.1002/hrm.10051

Garavan, T. N., Carbery, R., \& Rock, A. (2012). Mapping talent development: Definition, scope and architecture. European Journal of Training and Development, 36(1), 5-24. doi:http://0-dx.doi.org.wam. leeds.ac.uk/10.1108/03090591211192601

Gray, B. (2004). Informal learning in an online community of practice. Journal of Distance Education, 19(1), 20.

Griggs, V., Holden, R. J., Lawless, A. \& Rae, J. (2016) From reflective learning to reflective practice; assessing transfer. Studies in Higher Education, 1-12.

Kucherov, D., \& Zavyalova, E. (2012). HRD practices and talent management in the companies with the employer brand. European Journal of Training and Development, 36(1), 86-104.

Lave, J., \& Wenger, E. (1991). Situated learning: Legitimate peripheral participation. Cambridge: Cambridge university press.

Lewis, R. E., \& Heckman, R. J. (2006). Talent management: A critical review. Human Resource Management Review, 16(2), 139-154.

Nilsson, Staffan; Per-Erik Ellström. (2012). Employability and talent management: challenges for HRD Practices. European Journal of Training and Development, 36(1), 26-45.

Owen, H. H. (1997). Expanding our now: The story of open space technology. Berrett-Koehler Publishers.

Patton, M. Q. (1980). Qualitative evaluation methods. Beverly Hills, CA: Sage.

Pritchard, K., \& Fear, W. J. (2015). Credibility lost: attempting to reclaim an expert identity in an HR professional context. Human Resource Management Journal, 25(3), 348-363.

Raelin, J. A. (2002). “I Don't Have Time to Think!” versus the Art of Reflective Practice. Reflections, 4(1), 66-79.

Redford, K. (2005). Shedding light on talent tactics. Personnel Today, 22-22.

Senge, P., \& Kim, D. H. (2013). From Fragmentation to Integration: Building Learning Communities. Reflections, 12(4), 3-11.

Shani, A. B., \& Pasmore, W. A. (1985). Organization inquiry: Towards a new model of the action research process. In Warrick, D. D. (Ed.) Contemporary Organization development: Current Thinking and Aplications. (438-448). Illinois, Scott Foresman, Glenview.

Stoll, L., Bolam, R., McMahon, A., Wallace, M., \& Thomas, S. (2006). Professional Learning Communities: A Review of Literature. Journal of Educational Change. 7, 221-258.

Tarique, I., \& Schuler, R. S. (2010). Global talent management: literature review, integrative framework, and suggestions for further research. Journal of World Business, 45(2), 122-33.

Wang-Cowham, C. (2011). Developing talent with an integrated knowledge-sharing mechanism: An exploratory investigation from the Chinese human resource managers' perspective. Human Resource Development International, 14(4), 391.

Wenger, E. (2011). Communities of practice: A brief introduction. Watertown, MA: Harvard Business Press.

Wenger, E. (1998). Communities of practice: Learning, meaning, and identity. Cambridge: Cambridge University Press.

Wenger, E. C., \& Snyder, W. M. (2000). Communities of Practice: The Organizational Frontier. Harvard Business Review, 78(1), 139-145.

\section{The Authors}

Vivienne Griggs is Deputy Director (Student Education) at the University of Leeds, Lifelong Learning Centre. Vivienne has held roles as an HR Manager and as a senior lecturer in Human Resource Management specializing in Learning and Development, Leadership Development 
and Business skills. She is a Senior Fellow of the HEA and a member of the editorial board of Advances in Developing Human Resources. Areas of expertise and research interests: Learning and development, continuous professional development, reflective learning, evaluation/value of learning, knowledge sharing, teaching and learning strategies, HRD in the voluntary sector.

Jenny Allen has until recently worked as Head of HR and latterly as Head of Workforce at NHS Digital. She has accumulated 20 years of experience in leading and motivating teams to deliver high quality services and outputs in large and complex public sector organizations. Her HR practice is underpinned by full membership of the CIPD. Jenny has also in the past operated in a general management role, run her own successful HR consulting business and worked as an Associate Lecturer at several universities.

Jenny values the opportunity to contribute in an academic environment be that in terms of teaching and tutoring; review of academic texts; or as in the case of this study through collaborative practice based research. She is particularly interested in the professionalism of HR and HR professionals operating in this field, their expert contribution and measurement of value add. 
